\title{
Los grandes errores institucionales de la planeación del turismo en México
}

DOI: $10.22403 /$ UQROOMX/TYP01/04

Alberto Guevara Baltazar*

RESUMEN

El presente artículo, analiza la importancia de la planeación del turismo sustentable en México, para ello, se hace una breve descripción de los principales errores en los que ha caído el gobierno mexicano en esta materia. Posteriormente, se describen algunos recursos para reencausar la planeación. Por último, se formula un escenario preliminar hacia lo que podría ser el marco institucional para el fortalecimiento de las políticas públicas turísticas. Sobra decir que las reflexiones aquí planteadas constituyen un acercamiento a una problemática que no acaba por ser del todo conocida, pero que reclama mayor atención de todos los actores $y$ estudiosos en el tema.

Palabras Planeación del turismo, políticas públicas, fomento turístico,

CLAVE sustentabilidad, turismo.

"Universidad Autónoma del Estado de México / algueva26@yahoo.com 
Los grandes errores

institucionales de la planeación

del turismo en Mëxico

\section{Introducción}

La rápida transformación de las condiciones sociales como resultado de la evolución de las expectativas de las personas, la intensificación de los procesos de la globalización y la competencia cada vez más fuerte en los mercados, está vaciando de contenido y efectividad a las políticas turísticas tradicionales en América Latina.

En ese contexto, es necesario analizar las posibilidades reales de la planeación' del turismo sustentable en México, debido a que dicho fenómeno, si bien actúa dentro de una economía global, también opera paralelamente, dentro de un Estado-nación, lo cual implica necesariamente, luchas y negociaciones entre organizaciones público-gubernamentales, por la obtención de beneficios derivados de la ejecución de las políticas, que tienden a modificarse durante los procesos de política y/o decisión y administración y/ o ejecución.

En este sentido, a medida que el fenómeno turístico ${ }^{2}$ se hace más complejo como resultado de los cambios científicos, tecnológicos y la creciente competencia a nivel nacional e internacional, las empresas y los gobiernos toman decisiones en escenarios de mayor complejidad, expuestos a cambios rápidos e imprevistos, por lo que deben recurrir a un instrumento que disminuya la incertidumbre con el cual operan; en este caso, la planeación del turismo sustentable ${ }^{3}$ y sus técnicas, se transforman en un soporte básico, que les otorga una alta garantía de racionalidad en sus decisiones operativas.

No obstante, nuestro país ha ido rezagándose frente a las realidades de la sustentabilidad debido a que durante varias décadas se ha llevado a cabo

'En este trabajo se emplea el concepto de planeación expuesto por Ortega Blanke (1998: 249-250).

2 Desde una perspectiva fenomenológica, el turismo es concebido como más evolucionado y recnocedor de la complejidad humana. Al respecto véase Molina, 2004: 31 .

${ }^{3}$ El turismo sustentable propone nuevos principios de producción y líneas de acción en el consumo, donde se permitan aprovechar adecuadamente los recursos naturales y culturales, con la participación activa de las comunidades locales, las autoridades gubernamentales, ONG, comunidades académicas y empresas privadas, en un marco de vinculación intersectorial y de integración política. 
una planeación inadecuada, que no sólo ha transformado el aspecto físico de las zonas turísticas, sino que ha generado graves trastornos ecológicos: destrucción de ecosistemas, disminución de cantidad y calidad del agua, empobrecimiento y contaminación de los suelos, extinción de múltiples especies de la fauna, afectación severa de la flora, depredación pesquera y contaminación del mar, así como desintegración de actividades económicas tradicionales, aculturación, migración, fenómenos de crecimiento poblacional y urbano desordenados, falta de servicios públicos y pobreza extrema, entre otros. $^{4}$

A estas alturas resulta claro que, para subsistir dentro de esta planeación tradicional, ${ }^{5}$ se tiene que producir y ahondar la desigualdad entre estados $y$ regiones, hasta el punto en que grupos humanos enteros se vuelven inviables. Asimismo, estos impactos ambientales no sólo han generado deterioro ecológico, sino que a larga han creado imposiciones antidemocráticas y autoritarias por parte de los gobiernos locales y empresas privadas, generando resistencia civil, movimientos armados, violencia e ingobernabilidad. ${ }^{6}$

\footnotetext{
${ }^{4}$ Enrique Lef señala que el turismo sustentable debe ser ante todo un proyecto social y político que apunte hacia la descentralización y el ordenamiento ecológico de la producción, que ofrezca principios y orientaciones a los proyectos de la democratización de la sociedad, fundada en la participación directa de las comunidades en la apropiación y transformación de los recursos ambientales, y que no debe tener otra orientación que la de erradicar la pobreza, elevar la calidad de vida y satisfacer las necesidades básicas de las comunidades locales (Leff, 1998: 132).

${ }^{5}$ La planeación turística tradicional tiene diferentes características, sin embargo, por cuestiones de espacio sólo destacaremos tres: I) No se apoya en instrumentos efectivos, lo cual relega al turismo a un mero discurso que "la mano invisible" del mercado se encargara de materializar; 2) la existencia de una política cambiante, sin visión ni compromiso a largo plazo, que está sujeta a la prioridades de las autoridades gubernamentales, y 3) políticas de carácter sectorial e incrementalista, es decir, orientados al crecimiento de los indicadores (Molina, 2004: 15).

${ }^{6}$ Destaca el caso de Tepoztlán, Morelos, donde se quiso hacer un campo de golf, el proyecto implicaba la expropiación de $90 \%$ del agua a los agricultores tepoztecos. El pueblo se rebeló y erigió barricadas, ocupó el palacio municipal, nombró autoridades, desarrolló su autogestión e hizo caer al gobernador morelense $y$, a pesar de la represión gubernamental, el club de golf no se hizo. Como no se hizo tampoco otro club de golf en Xochimilco, por la resistencia de sus pobladores. El caso más reciente es el del municipio de San Salvador Atenco, en el Estado de México, donde se pretendió imponer de igual manera el aeropuerto internacional con tenido terribles consecuencias sociales, ecológicas y culturales a la región.
} 
Los grandes errores

institucionales de la planeación

del turismo en Mëxico

\section{Las grandes fallas del sistema de planeación turística en México}

En efecto, no obstante que en México ya se han comenzado a adoptar e implementar los principios internacionales de la planeación del turismo sustentable, en algunas regiones y municipios del país, se siguen tomando decisiones gubernamentales de planeación contradictorias -con el modelo de administración pública conservador, pero en el contexto de una economía global-, derivando principalmente a inercias burocráticas, falta de coordinación y cooperación en los tres ámbitos de gobierno, excesos regulatorios tanto al interior del gobierno como hacia el exterior de los particulares, que inhiben la creatividad y por ende, la capacidad de adaptación de los inversionistas nacionales e internacionales.

Ello ha conducido, en primer término, a que los esquemas de la planeación del turismo mexicano tengan fallas de origen muy claras, que poco se han atendido, estos errores tienen que ver al menos con los siguientes aspectos:

I) La persistencia en los contrastes regionales, interregionales e intraregionales que caracterizan a las grandes regiones económicas de nuestro país. En estos estudios se refleja con claridad la tendencia a desarrollar grandes ejes económicos, que unen grandes ciudades a manera de corredores, en donde la inversión, la actividad económica y turística se concentran, mientras que en la periferia, particularmente en las regiones menos accesibles, la marginación y la pobreza crecen en la misma medida que estos ejes se enriquecen y capitalizan. Se privilegia a los Centros Integralmente Planeados sobre el desarrollo del turismo rural (Calva, 1998: II2).

2) En ese sentido, los gobiernos estatales carecen de mecanismos e instrumentos administrativos efectivos para coordinar a los gobiernos municipales y empresarios locales en la gestión del turismo. ${ }^{7}$

${ }^{7}$ El redimensionamiento del Estado mexicano y la economía de libre mercado han sido las causas de la descentralización de funciones en el gobierno federal. Por ello, la Secretaría de Turismo (SECTUR) firmó en 1993 un convenio con los gobiernos estatales, mediante el cual delega ciertas funciones administrativas, transformándolas en un tipo de delegaciones federales, pero sin los recursos económicos, humanos y materiales necesarios para que estas puedan 
3) Asimismo, la información que alimenta la planeación y a los programas de desarrollo, capacitación, promoción e inversión turística en los municipios es muy limitada y carece de niveles de confiabilidad necesarios (Hiernaux, 2000: 47-48).

No obstante, hay municipios que no estaban considerados como turísticos y ahora están aumentando su nivel de competitividad en forma rápida. Ejemplo de esto son Hidalgo (deportes extremos) Tlaxcala (ferias y fiestas) San Luis Potosí (ecoturismo) Veracruz (arqueología), Chiapas y Oaxaca (Cultura), etcétera (Programa Estratégico de Turismo del Estado de México, 2002: 59).

4) La oferta de los municipios en el país se presenta en el mercado de manera desarticulada, es decir, es individual y presenta desorganización productiva y comercial en las formas como se manifiesta a la demanda (Boullón, 1999).

5) Las grandes ciudades de México en proceso de urbanización están influyendo en el desbordamiento de la mancha urbana sobre los municipios rurales del país, impactando sus recursos naturales.

6) Los gobiernos municipales carecen de recursos económicos y tecnológicos para convertirse en líderes de proyectos ecoturísticos; asimismo, en la praxis los ayuntamientos no tienen suficientes especialistas que articulen y potencien las políticas de descentralización y coordinación intersectorial e interregional, toda vez que las grandes estrategias turísticas se concentran ahora en las comunidades locales (García del Castillo, 46: 1999).

7) La planeación turística en los municipios carece absolutamente de una gestión pública de largo plazo que se traduzca en experiencias acumuladas y sistemas de evaluación y desempeño que permitan, por un lado, evaluar los avances en los programas de desarrollo turístico y, por otro, calificar la actuación de los funcionarios públicos improvisados,

funcionar. Esta delegación de funciones puso a los gobiernos estatales en el trance de responder a la necesidad de coordinar a los gobiernos municipales. Es decir, mientras que la Secretaría de Turismo trabaja en 32 entidades federativas, los gobiernos estatales deben atender las expectativas de una gran cantidad de municipios, con recursos limitados. (Programa Estratégico de Desarrollo Turístico del Estado de México, 2002: 10) 
Los grandes errores

institucionales de la planeación

del turismo en Mëxico

que carecen de conocimiento y compromiso, debido a que se encuentran supeditados a los vaivenes electorales de cada tres años.

Esto es por demás nocivo e insano porque cada administración actúa sin evaluar los avances de las administraciones anteriores, lo que a la larga conlleva a un constante inicio y reinicio de iniciativas y el desperdicio de recursos de toda índole (Giandomenico, 2002).

8) En ese sentido, el concepto regional del desarrollo turístico en los estados presenta retos de cooperación y organización a los actores locales que no han sido enfrentados acertadamente porque no hay liderazgo. Es más fácil trabajar de manera aislada y obtener resultados que hacerlo de manera cooperativa, coordinada y corresponsable.

9) Esto ha conducido a que las autoridades de los ayuntamientos planteen sus propias metas, objetivos, programas, proyectos y acciones a partir exclusivamente de sus planes trianuales. Situación que ha traído como consecuencia, vacíos y traslapes significativos en las acciones y la solución de problemáticas reales en las distintas regiones del país, tomando en cuenta parcialmente colaboraciones con otras dependencias federales y estatales en el ámbito operativo. Esto representa al final, la sensación de aislamiento funcional entre los distintos sectores y lo que es peor aún, el desperdicio de recursos y la repetición de esfuerzos entre diversas áreas.

10) En suma, si bien existe en la mayoría de los ayuntamientos del país una visión gubernamental de largo plazo para transformarlos en polos turísticos, en la realidad no hay voluntad ni conocimiento adecuado porque se sigue percibiendo al turismo como una actividad económica, no como un fenómeno complejo que abarca todos los ámbitos de la actividad humana, y que se diferencia de otras actividades en que la producción y el aprovechamiento de bienes y servicios turísticos depende del desplazamiento de personas de su lugar de residencia al destino que logra convencerlos de vivir una nueva experiencia, y no de la distribución de los productos a los mercados demandantes. Lo cual implica que el turista está haciendo uso de la planta turística desde que sale de su domicilio hasta que regresa, de ahí que es importante contar con comunidades seguras, atractivas, competitivas y de calidad para 
mantenerlo satisfecho, de lo contrario el turista no vuelve más y el efecto multiplicador desde el punto de vista social y económico se disipa.

\section{Elementos necesarios para}

\section{la planeación del turismo}

Hasta ahora se han planteado algunos de los errores y elementos que le dan forma a la planeación del turismo sustentable en México y lo que, de acuerdo con los principales teóricos, constituye un sistema intersectorial de cooperación y coordinación. Sin embargo, esta planeación hoy día está ligada a nuestro sistema federal y a la fuerte interacción entre diversas instancias de gobierno con vida e interés propios.

En efecto, en la actualidad, los gobiernos subnacionales cuentan con cierto margen de acción relativamente independiente, lo cual puede traducirse en tensiones constantes de diferente intensidad y complejidad, con el gobierno central o entre ellos. Así, los ajustes de la planeación turística -dentro del diseño jurídico institucional y/o administrativo- significa una reconstitución de poder, en el cual se involucran elementos políticos, estructurales de funcionamiento y competencia.

En los años recientes, la natural inclinación del gobierno nacional por seguir atendiendo la actividad turística en los municipios se ha topado con una mayor resistencia y oposición por parte de los gobiernos estatales.Aunque el gobierno federal ha optado por aplicar sus decisiones en terrenos financieros y de política, las posturas estatales tienden a cuestionar este tipo de posiciones y plantear disputas de carácter constitucional ante la Suprema Corte de Justicia de la Nación (Fix-Fierro, 2003: 187).

No obstante, las controversias constitucionales han ido superando la dimensión jurídica y se han incorporando otro tipo de criterios que dan una visión más amplia de lo que constituye el fenómeno municipal. Al tratar de demostrar una mayor capacidad para entender $y$ atender los problemas turísticos en los municipios, instancias federales y gobiernos estatales han construido ya un margen municipal $-y$ en alguna medida uno estatal- en el que ya no existe un solo tipo de municipio, que es intangible y abstracto, sólo reconocible por su papel como la instancia más cercana al ciudadano (Quintana Roldán, 2002: 6). 
Los grandes errores

institucionales de la planeación

del turismo en Mëxico

Ahora se reconoce que bajo las denominaciones genéricas de municipio y ayuntamiento se encuentran grupos humanos y territorios enteros que pueden ser municipios de vocación turística consolidada, en transición o en formación, con graves problemas de saturación, agotamiento de recurso naturales y contaminación; o bien, entornos rurales o semiurbanos en los que los rasgos de relativa modernidad o de desarrollo incipiente, coexisten con fenómenos de atraso, marginación y despoblamiento (García del Castillo, 1999: 46).

Este panorama de contrastes en los municipios turísticos propicia igualmente dos variables: su condición urbana o rural y su posición en el mapa electoral estatal. La influencia de los procesos electorales es determinante en la situación de los ayuntamientos, pues la evidencia disponible muestra que existe una estrecha relación entre el tipo de vínculo que se establece entre éstos y los gobiernos estatales y la pertenencia $\circ$ no al mismo partido político. El cambio de mayoría en cualquiera de los dos ámbitos de gobierno hace que, con algunas excepciones, se integren redes de cooperación o conflicto en el quehacer turístico a partir de la identidad de partido político. (Guillén y Ordoñez, 1998: 172).

Esta condición afecta el desarrollo del turismo debido a que los mecanismos de coordinación interinstitucional dependen de actores -cuya naturaleza, ideología y posición puede ser muy diferente- que decidan o no cooperar para alcanzar objetivos de interés común.Al permanecer limitadas las posibilidades de desarrollo de las redes de cooperación en el turismo, por este sesgo partidista, se obliga a que los ayuntamientos asuman estrategias que pueden ser de gestión en "solitario" -entendido esto como el desarrollo de programas y políticas turísticas sustentadas exclusivamente en recursos y facultades propias- o de abierta búsqueda de apoyo en el nivel federal, como una forma de atenuar el control que ejerce el gobierno estatal (Guillén y Ordoñez;|998;1 I6).

En efecto, conforme los procesos políticos avancen hacia la generalización de la pluralidad democrática en los municipios, los gobiernos deberán incorporar un número cada vez mayor de políticas públicas turísticas, ${ }^{8}$ relacionadas con la administración pública y con la gestión de

${ }^{8}$ Las políticas públicas tienen un enfoque multidisciplinario, su origen proviene de los Estados Unidos de Norteamérica, en la década de los 40, sus fundadores fueron Harold Laswell y Charles Limdblom. Tienen una doble dimensión: por una parte se interesan "en el 
necesidades concretas. Esto deberá de propiciar también una mayor comprensión de las fuentes de legitimidad que corresponden a cada ámbito de gobierno y a cada una de sus responsabilidades $y$, por ende, una mayor profundización en la distribución de competencias y recursos en la planeación del turismo.

\section{A manera de conclusión}

Hoy es imprescindible construir nuevos análisis y propuestas metodológicas respecto a la sustentabilidad de la planeación turística, la razón es evidente, la mitad de la población total de nuestro país apenas satisface sus necesidades básicas y vive cotidianamente la falta de expectativas sociales, por la marginación y por la erosión del medio ambiente.

Por consiguiente, en la conformación de un nuevo marco institucional de planeación y cooperación para el turismo, consideramos que tendrán que ocurrir algunos procesos de ajuste en nuestro sistema federal, siendo de mayor relevancia los siguientes:

I) La generalización de la pluralidad democrática en los municipios propiciará que la planeación del turismo se vea sometida a presiones por parte de los actores involucrados y de la población beneficiaria. Es decir, es probable que se configure un esquema de interacciones intergubernamentales en el que, en sentido vertical, la población beneficiaria ejerza presión hacia las autoridades para que contemplen sus necesidades y demandas en dicha actividad.

En sentido horizontal, otras administraciones públicas del mismo ámbito o ámbitos diferentes, propiciarán que las administraciones nuevas asuman compromisos de carácter financiero, organizativos y programáticos que coadyuven al logro de objetivos y metas que difícilmente alguna administración municipal en "solitario" puede alcanzar. El resultado de estas presiones será que paulatinamente todas las administraciones municipales convergerán en

proceso" de la política y por otra en "las necesidades de inteligencia" de este proceso. La tarea de la primera pretende desarrollar la ciencia del diseño y ejecución de las políticas a partir del uso de los métodos de investigación de las ciencias sociales y la sociología. La segunda dimensión, pretende mejorar el contenido de la información e interpretación; por tanto se enriquece de las "ciencias duras," tales como: la micro y macro economía, la investigación de operaciones, el análisis de sistemas, el análisis estratégico, la ingeniería de sistemas, la modelación matemática y la estadística aplicada (Aguilar Villanueva, 2002: 52). 
Los grandes errores

institucionales de la planeación

del turismo en Mëxico

la planeación del turismo hacia nuevas formas y criterios de funcionamiento y organización homogénea, aunque no necesariamente idénticas (García del Castillo, 1999: 46).

2) La incorporación creciente de experiencias innovadoras exitosas en la formulación, implementación y evaluación de programas turísticos a todos los ámbitos de gobierno, deberá ser una constante para prevenir errores, lo que reducirá los enormes costos económicos de consultoría y asesoría que esta actividad esta generando.

3) Será necesario intensificar medidas encaminadas a la acumulación y aprovechamiento del conocimiento producido por la gestión pública en el turismo. Esto implicará reforzar las estrategias de comunicación interna entre los grupos interinstitucionales y organizaciones con funciones similares y, sobre todo, de políticas de capacitación y de desarrollo de personal que trasmitan la experiencia de generaciones maduras, a las que se irán incorporando a las labores gubernamentales del turismo.

4) Será necesario el respaldo académico interdisciplinario en la planeación del turismo, debido a que se requerirán construir matrices metodológicas y escenarios de impacto por actividad, es decir, elaborar estudios prospectivos multidisciplinarios (administrativos, arquitectónicos, mercadológicos, ecológicos, geográficos, sociológicos, económicos, financieros, entre otros), donde la comunidad local y los diversos actores involucrados, deberán de interactuar, coordinarse y se privilegiará la construcción de consensos (Rosado-May, 2000: 160-16I).

5) Los alcances de la planeación no deberán atribuirse exclusivamente a los recursos técnicos y humanos con que se cuente, sino que, ante todo, dichos alcances deberán evaluarse en función del marco estructural y coyuntural de condiciones económicas, culturales e institucionales de la región, estado o municipio.

Es decir, deberá ser una planeación de verdadero desarrollo sustentable, donde se conserve la cultura, las tradiciones y los ecosistemas de los destinos turísticos y no sólo de crecimiento económico. Hasta ahora, uno de los objetivos más comunes en los estudios mercadológicos del turismo ha sido una elevada tasa de crecimiento económico per cápita, soslayando el hecho de que -en el marco estructural del país- el cumplimiento de este objetivo aislado produce, por lo general, una situación de mayor deterioro ecológico, 
descomposición social, polarización económica y marginalidad en las comunidades anfitrionas.

6) Por último, la planeación del turismo sustentable, desde la prospectiva gubernamental, deberá implicar necesariamente desarrollar estudios sociológicos que expliquen ¿quiénes son los actores? ¿qué piensan? ¿qué hacen? ¿qué interacción tienen entre ellos mismos? ¿cuáles son sus intereses? etcétera, es decir, será necesario interpretar los sentimientos o creencias "profundas" o aquellos motivos "escondidos" o "inconscientes" del sujeto social.

Ello conducirá a elaborar investigaciones turísticas, de un doble tipo de racionalidad. Por un lado, una racionalidad económico-administrativa (costo y beneficio-eficacia y eficiencia), y otro legal-sociopolítico, que suponga el cumplimiento del orden jurídico dentro de un Estado de derecho, para la conciencia ecológica y la convivencia democrática a fin de equilibrar intereses de poder de cada grupo involucrado en la planeación.

\section{FUENTES CONSULTADAS}

Aguilar, Villanueva Luis F. (comp.) (2002). El estudio de las políticas públicas. México: Porrúa.

Boullón, Roberto C. (1999). Los municipios turísticos. México:Trillas.

Calva, José Luis (1998). Los campesinos y su devenir en las economías de mercado. México: Siglo XXI.

Fix-Fierro, Héctor (2003). "Controversias constitucionales y federalismo. Un análisis jurídico-político”, en Jacqueline Martínez Uriarte y Alberto Díaz Cayeros (coords). De la descentralización al federalismo. Estudios comparados sobre el gobierno local en México. México: Porrúa.

Giandomenico, Majone (2002). Evidencia, argumentación y persuasión en la formulación de políticas. México: FCE.

García de Castillo, Rodolfo (1999). "Gobierno locales y políticas públicas en México. Perspectivas en el nuevo federalismo" Revista de Ciencias Sociales y Humanidades Políticas Públicas para el siglo XXI. UAM Iztapalapa. Año 19, núm. 46, julio-diciembre de 1999.

Guillén Tonathiu y Guillermo Ordóñez (1998). El municipio y el desarrollo social de la frontera norte. México: El Colegio de la Frontera Norte. 
Los grandes errores

institucionales de la planeación

del turismo en Mëxico

Leff, Enrique (1998).“Coloquio de invierno”, La situación de la vida democrática, t. I. México: UnAM, CONACULTA-FCE.

Hiernaux Nicolás, Daniel (2000). "Nuevos derroteros de la investigación turística”, en Neptalí Monterroso Salvatierra y Lilia ZizumboVillarreal (coords.) Investigación turística.Toluca, México: Facultad de Turismo, UAEM.

Molina, Sergio (2004). Fundamentos del nuevo turismo. México: Centro de Emprendimiento e innovación.

Rosado-May, Francisco J. (2000) "Modelos para la planeación y el estudio del turismo como actividad económica", en Neptalí Monterroso Salvatierra y Lilia ZizumboVillarreal (coords.) Investigación turística. Toluca, México: Facultad de Turismo, UAEM.

Programa Estratégico de Turismo del Estado de México (2002). Dirección General del Turismo del Gobierno del Estado de México, Toluca.

SECTUR (2002). Turismo alternativo. Una nueva forma de hacer turismo, I, México:SECTUR.

Ortega Blanke,Arturo (1998). Diccionario de Planificación económica, política, social y administrativo. México:Trillas.

Quintana Roldán, Carlos (2002). Derecho Municipal. México: Porrúa. 